\title{
Phase I/II studies of combination chemotherapy with S-1 and platinum in patients with previously untreated metastatic or recurrent gastric cancer
}

\author{
YOON-KoO KANG \\ Division of Oncology, Asan Medical Center, University of Ulsan College of Medicine, 388-1 Pungnap-dong, Songpa-gu, Seoul 138-736, Korea
}

\begin{abstract}
Despite the progress in treatment protocols, gastric cancer remains a challenging disease. Systemic chemotherapy is of crucial importance for patients with metastatic or recurrent disease, and new developments in chemotherapy regimens have been seen in recent years. An oral 5-fluororacil (5-FU) agent, S-1, is emerging, with promising results. Various S-1 combination regimens, mostly with cisplatin, are being examined extensively, and the combination of $S-1$ with oxaliplatin is the focus of recent studies. In this study, phase I/II studies of combination chemotherapy with $S-1$ and platinum in patients with metastatic or recurrent gastric cancer were reviewed. We found that the combination of S-1 plus cisplatin was highly active against advanced gastric cancer, with a favorable toxicity profile. The response rates were $53 \%-74 \%$ in Japan, $\mathbf{4 7 . 6} \%$ in Korea, and $51 \%$ in the United States and Europe. There is no internationally accepted standard care for patients with advanced gastric cancer yet, but S-1 is likely to replace infusional 5-FU, and oxaliplatin may represent an alternative to cisplatin in the near future. More innovative therapies, particularly with molecular-targeted drugs, are needed to meet the needs of patients in the era of tailored medicine.
\end{abstract}

Key words S-1· Chemotherapy · Gastric cancer

\section{Introduction}

Despite the progress made in its management, advanced gastric cancer remains a challenging disease [1]. The populations of many Asian countries are at high risk for gastric cancer, and in fact, its incidence and death rate are still high in Korea [2]. Patients with gastric cancer often present with metastatic disease, and even in those with resectable disease, rates of recurrence are high.

Offprint requests to: Y.-K. Kang

Received: December 12, 2007 / Accepted: May 20, 2008
Systemic chemotherapy plays a crucial role in treatment [3-5].

Although combination chemotherapy has been studied extensively, there is no internationally accepted standard of care for patients with advanced gastric cancer [4-7]. Worldwide, the combination of 5fluorouracil (5-FU) and cisplatin is a mainstay in the treatment of advanced gastric cancer. Recently, oral fluoropyrimidines have been emerging as a breakthrough treatment [6]. The use of oral agents has potential advantages, from patient convenience to avoiding the need for indwelling venous access and infusion pumps $[7,8]$. An oral fluoropyrimidine, S-1, is a fourthgeneration fluoropyrimidine containing tegafur, 5chloro-2, 4-dihydroxypyridine, and potassium oxonate [9]. Interesting results have been accumulating in evaluating S-1 combination therapies, particularly with platinum drugs. In this study, we reviewed phase I/II studies of combination chemotherapy with S-1 and platinum in patients with metastatic or recurrent gastric cancer.

\section{S1 + cisplatin trials in Asia}

The combination of S-1 and cisplatin is logical, given the biochemical modulation it offers: the inhibition of methionine uptake into tumor cells by cisplatin results in the enhancement of 5-FU cytotoxicity [10]. Since the first phase I trial of S-1 in 1997 [11], many phase I/II studies have been conducted in Japan and have yielded promising results.

One of the notable results of the phase II studies of S-1 and cisplatin was reported by Koizumi et al. [12]. S-1 was administered daily at a dose of $80 \mathrm{mg} / \mathrm{m}^{2}$ per day for 3 weeks, followed by a 2-week rest, with cisplatin at $60 \mathrm{mg} / \mathrm{m}^{2}$ given on day 8 . This regimen had a 5 week cycle, and the response rate was $74 \%$. Using the same regimen, the authors of two other studies also reported high response rates, of $67 \%$ and $66.7 \%$, respec- 
Table 1. S-1 + cisplatin: Japanese phase I/II studies

\begin{tabular}{|c|c|c|c|c|c|c|}
\hline Author & $\begin{array}{c}\text { Cycle interval } \\
\text { (weeks) }\end{array}$ & $\mathrm{S}-1\left(\mathrm{mg} / \mathrm{m}^{2} \mathrm{bid}\right)$ & Cisplatin $\left(\mathrm{mg} / \mathrm{m}^{2}\right)$ & $n$ & $\begin{array}{l}\mathrm{RR} \\
(\%)\end{array}$ & $\begin{array}{c}\text { Cisplatin DI } \\
\text { (/ } 3 \text { weeks) }\end{array}$ \\
\hline Nakata [10] & 6 & $40-60 \times 4$ weeks & $4 ;$ D $1-5,8-12,15-19,22-26$ & 24 & 55 & \\
\hline Tsujitani [15] & 6 & $40 \times 4$ weeks & $5-10 ;$ D $1,3,5 \times 4$ weeks & 15 & 53 & \\
\hline Koizumi [12] & 5 & $40 \times 3$ weeks & $60 ;$ D 8 & 19 & 74 & $36 \mathrm{mg} / \mathrm{m}^{2}$ \\
\hline Baba [14] & 5 & $40 \times 3$ weeks & $60 ; \mathrm{D} 8$ & 12 & 67 & $36 \mathrm{mg} / \mathrm{m}^{2}$ \\
\hline Sato [16] & 4 & $40 \times 2$ weeks & $70 ; \mathrm{D} 8$ & 11 & 73 & $52.5 \mathrm{mg} / \mathrm{m}^{2}$ \\
\hline Hyodo [17] & 3 & $35 \times 2$ weeks & $20 ;$ D 1,8 & 18 & 61 & $40 \mathrm{mg} / \mathrm{m}^{2}$ \\
\hline
\end{tabular}

$\mathrm{D}$, day; DI, dose intensity

Table 2. Dose escalation and DLTs in Korean phase I study of S-1 + cisplatin (during first two cycles)

\begin{tabular}{lcccc}
\hline Dose level & $\mathrm{S}-1\left(\mathrm{mg} / \mathrm{m}^{2}\right.$ bid $)$ & Cisplatin $\left(\mathrm{mg} / \mathrm{m}^{2}\right)$ & No. of patients & No. of patients with DLT \\
\hline 1 & 30 & 60 & 6 & $1^{\mathrm{a}}$ \\
2 & 35 & 60 & 3 & 0 \\
3 & 40 & 60 & 3 & 0 \\
4 & 45 & 60 & 6 & $1^{\mathrm{b}}$ \\
5 & 50 & 60 & 3 & $2^{\mathrm{c}}$ \\
\hline
\end{tabular}

DLT, dose-limiting toxicity

${ }^{a}$ The second treatment cycle was delayed for more than 2 weeks due to grade 2 leukopenia and infection

${ }^{\mathrm{b}}$ Grade 3 asthenia and grade 3 anorexia had not improved to at least grade 1 within 2 days

${ }^{\mathrm{c}}$ Grade 3 diarrhea was sustained for more than 2 days despite antidiarrheal medication; grade 3 febrile neutropenia and grade 3 nausea/ vomiting developed

tively [13, 14]. In other studies, S-1 was fixed at a standard dose of $80 \mathrm{mg} / \mathrm{m}^{2}$ per day and the optimal dose of cisplatin was explored with different cycles, and these regimens showed antitumor activity with response rates ranging from $53 \%$ to $73 \%$ [15-17]. Toxicities were generally manageable. Leucopenia, neutropenia, anemia, and diarrhea were the most common adverse effects. As shown in Table 1, however, the dose intensity of cisplatin in most studies was lower than the dosages that have been widely accepted as reference regimens in advanced gastric cancer $\left(20-25 \mathrm{mg} / \mathrm{m}^{2}\right.$ per week) $[12,14,16,17]$.

Interestingly, one of the Japanese research groups compared a 4-week-on and 2-week-off schedule with a 2-week-on and 1-week-off schedule for S-1 [18]. In the retrospective analysis, they reported that patients following the 2-week-on and 1-week-off schedule had fewer adverse reactions and improved patient compliance. They concluded that the 2-week regimen may mitigate the adverse reactions and prolong the medication period.

With this background, a phase I/II study of a 3-week combination of S-1 plus cisplatin was conducted in Korea [8]. S-1 was given daily for 2 weeks, followed by 1 week of rest, with a fixed dose of cisplatin at $60 \mathrm{mg} / \mathrm{m}^{2}$ on day 1 . The starting dose of S- 1 was $60 \mathrm{mg} / \mathrm{m}^{2}$ per day (level 1) on day 1 to day 14, every 3 weeks. In the phase I portion of the study, the dose of $\mathrm{S}-1$ was escalated by $5 \mathrm{mg} / \mathrm{m}^{2}$ per dose up to $100 \mathrm{mg} / \mathrm{m}^{2}$ per day (level 5) unless the maximum-tolerated dose (MTD) was achieved, with the observation of two cycles at each dose level. At level 5, two of three patients developed grade 3 nausea/vomiting or febrile neutropenia (Table 2); therefore, the MTD was defined at level 5. The recommended dose was determined to be that given at level $4\left(90 \mathrm{mg} / \mathrm{m}^{2}\right.$ per day); however, in the phase II portion of the study, poor hematologic recovery in 20 patients enrolled in the study resulted in a reduction of the $\mathrm{S}-1$ dose to $80 \mathrm{mg} / \mathrm{m}^{2}$. Of the total of 42 patients assessable in the phase II study, 20 achieved a partial response, indicating that the objective response rate was $47.6 \%$. At a median follow-up duration of 12.1 months (range, 9.8-23.2 months), the median progression-free survival and median overall survival were 5.3 months and 10.0 months, respectively (Fig. 1). The most common grade 3 or 4 hematologic toxicities were anemia and granulocytopenia, while the most common nonhematologic toxicities were asthenia and anorexia. There was no febrile neutropenia.

According to the Japanese post-marketing survey of $\mathrm{S}-1$, more than half of the patients discontinued the treatment within the first two treatment cycles when S-1 was given for 4 consecutive weeks followed by a 2-week rest [19]. Because most toxicity occurred during the third week of the first round of administration, the provision of a drug-free interval in the third week of the drug cycle is legitimate to minimize the incidence of adverse reactions and to maximize the efficacy. The Korean phase I/II study of a 3-week regimen of S-1 and cisplatin noted above [8] seems to be reasonable and provides an important treatment option for patients with advanced gastric cancer. 
Table 3. Regimens with oxaliplatin in first-line treatment of advanced gastric cancer

\begin{tabular}{lllll}
\hline Authors & \multicolumn{1}{c}{ Treatment } & RR (\%) & TTP (months) & OS (months) \\
\hline Lourvet et al. [26] & FOLFOX 6 & 45 & 4.3 & 7.3 \\
De Vita et al. [27] & FOLFOX 4 & 38 & 6 & 1.1 \\
Cavanna et al. [28] & FOLFOX 4 & 42.9 & 7.7 & 10 \\
Oh et al. [29] & Modified FOLFOX 4 & 50 & 9.6 & 11.2 \\
Lee et al. [30] & FOLFOX IRI & 66.7 & 14.8 \\
\hline
\end{tabular}

RR, response rate; TTP, time to progression; OS, overall survival; FOLFOX, oxaliplatin-5-FU-leucovorin; IRI, irinotecan

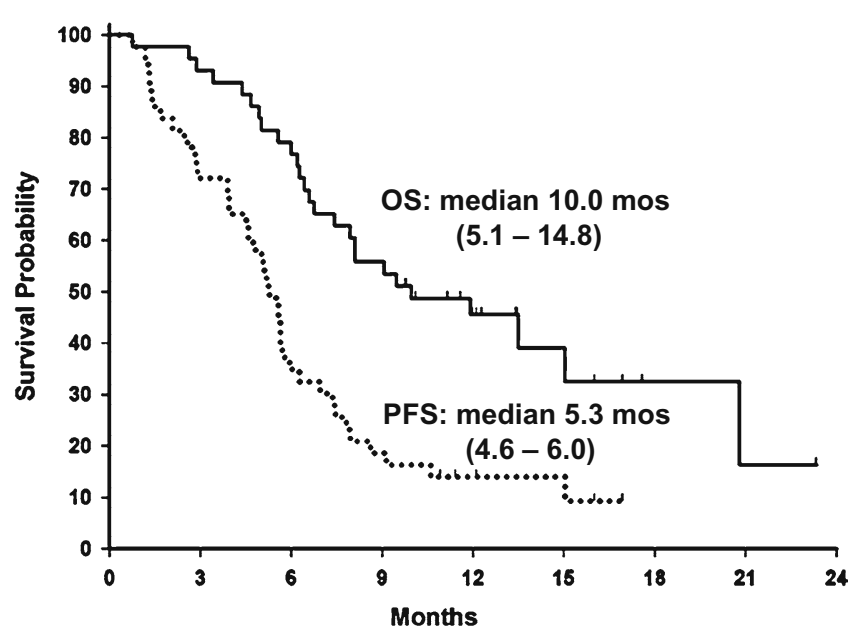

Fig. 1. Progression-free survival $(P F S)$ and overall survival $(O S)$. Median FU duration: 12.1 months (range 9.8-23.3). $F U$, Follow-up; mos, months

\section{S1 + cisplatin trials in the West}

In contrast to the results seen in Japan and Korea, a daily S-1 dose of $80 \mathrm{mg} / \mathrm{m}^{2}$ was intolerable in the West due to severe diarrhea [20,21]. Phase I pharmacokinetic studies of $\mathrm{S}-1$ in patients with advanced gastric cancer concluded that the MTD of S-1 was $50 \mathrm{mg} / \mathrm{m}^{2}$ per day $[21,22]$. The ethnic variation in the tolerable dose of S-1 is possibly explained by differences in metabolism by cytochrome $\mathrm{P} 450$ related to genetic polymorphisms in CYP2A6 [23]. A prospective study of S-1 is presently underway in Korea to study the genetic association of pharmacokinetics, toxicity, and CYP2A6 polymorphism. In the West, the recommended dose of cisplatin in combination with $\mathrm{S}-1$ was $75 \mathrm{mg} / \mathrm{m}^{2}$ on day 1 of a $4-$ week cycle [21]. A multicenter phase II trial of S-1 plus cisplatin in patients with untreated advanced gastric cancer in the United States and Europe showed encouraging results with that regimen [24]. The overall response rate was $51 \%$, with acceptable toxicity. On the basis of this phase II study [24], there is an ongoing phase III global study called FLAGS (First-Line Advanced Gastric Cancer Study), which compares overall survival in patients receiving S-1 plus cisplatin versus those receiving 5-FU plus cisplatin.
According to the phase I/II studies of S-1 plus cisplatin in Asia and the West, the combination of S-1 plus cisplatin is highly active against advanced gastric cancer, with a favorable toxicity profile.

\section{Recent developments in new platinum drugs}

Recently there has been renewed interest in platinumbased chemotherapy. Oxaliplatin is a third-generation platinum analog with different activity from that of cisplatin. Oxaliplatin retains activity even against some cancer cells with acquired resistance to cisplatin, with a more favorable toxicity profile [25]. Oxaliplatin has been widely acknowledged to be active against colon cancer, particularly in combination with 5-FU.

As first-line chemotherapy in patients with advanced gastric cancer, five phase II studies of oxaliplatin in combination with 5-FU have yielded response rates in the range of $38 \%$ to $66.7 \%$ [26-30]. Time-toprogression and overall-survival data are similar in these trials. Four of these trials studied combinations of oxaliplatin and 5-FU and leucovorin, while irinotecan was also added in one study (Table 3 ). The safety profile of the 5-FU/oxaliplatin regimen is favorable, with low rates of grade 3-4 toxicities.

More recently, Al-Batran et al. [31] reported the results of a phase III trial comparing 5-FU-leucovorinoxaliplatin (FLO) with 5-FU-leucovorin-cisplatin (FLC), showing response rate and time-to-progression endpoints, as well as toxicity levels, favoring the FLO arm. This suggests that oxaliplatin can be substituted for cisplatin as first-line therapy.

\section{S1 + oxaliplatin}

In Korea, a phase I/II study of S-1 plus oxaliplatin in three cycles as first-line therapy in patients with recurrent and/or metastatic gastric cancer is ongoing [32]. In this study, S-1 was administered for 2 weeks followed by 1 week of rest, with oxaliplatin given on day 1 . The dose of oxaliplatin was fixed at $130 \mathrm{mg} / \mathrm{m}^{2}$, and the dose of S-1 was escalated from $35 \mathrm{mg} / \mathrm{m}^{2}$ bid to a maximum of $50 \mathrm{mg} / \mathrm{m}^{2}$ bid by $5 \mathrm{mg} / \mathrm{m}^{2}$ increments at each dose 
level. The MTD was not reached up to the highest dose level of S-1; therefore, the phase II study was conducted at the S-1 dose of $50 \mathrm{mg} \mathrm{m}$ m $^{2}$ bid in combination with $130 \mathrm{mg} / \mathrm{m}^{2}$ of oxaliplatin. A total of 47 patients were enrolled in the phase II study. Twenty-six partial responses were observed, and the objective response rate was $55.3 \%$ on an intention-to-treat basis and $60.5 \%$ in the perprotocol population. This 3-week, S-1-plusoxaliplatin regimen seems to be very promising against advanced gastric cancer.

\section{Future directions}

The Japanese Clinical Oncology Group conducted a large phase III study comparing 5-FU alone, S-1 alone, and a combination of irinotecan and cisplatin, and concluded that S-1 was not inferior to 5-FU. This result suggests that $\mathrm{S}-1$ could replace intravenous 5-FU [33]. Furthermore, the combination of S-1 and cisplatin can be regarded as a new first-line standard regimen for the treatment of advanced gastric cancer based on the recent results of the phase III SPIRITS trial, showing that the combination of S- 1 and cisplatin was superior in regard to overall survival when compared with S-1 alone [34]. And, if the currently ongoing Western FLAGS trial demonstrates that S-1 plus cisplatin is superior to 5-FU plus cisplatin, $\mathrm{S}-1$ plus cisplatin can become a global standard regimen for the treatment of advanced gastric cancer. However, the dose schedules of S-1 plus cisplatin differ among countries; Japan (5week cycle), Korea (3-week cycle), and United States (4-week cycle), and this difference could be an obstacle to the further development of chemotherapy based on the S-1-plus-cisplatin combination. Further down the road, oxaliplatin will likely replace cisplatin as the platinum agent of choice.

As we move toward the tailoring of therapy to the individual patient, we have to consider the balance between the chemotherapy-related toxicity and each patient's quality of life. More innovative combinations with new drugs, molecular-targeted drugs in particular, will offer potential opportunities to enhance the efficacy of combinations of S-1 and platinum agents.

\section{References}

1. Parkin MD, Bray F, Ferlay J, Pisani P. Global cancer statistics, 2002. CA Cancer J Clin 2005;55:74-108.

2. Lee JY, Kim HY, Kim KH, Jang HD, Kim JB, Lee JH, et al. No changing trends in incidence of gastric cardia cancer in Korea. J Korean Med Sci 2003;18:53-7.

3. Ajani JA. Evolving chemotherapy for advanced gastric cancer. Oncologist 2005;10 (Suppl 3):49-58.
4. Wagner AD, Grothe W, Haerting J, Klebr G, Grothey A, Fleig WE. Chemotherapy in advanced gastric cancer: a systematic review and meta-analysis based on aggregate data. J Clin Oncol 2006;24:2903-9.

5. Scartozzi M, Galizia E, Verdecchia L, Berardi R, Antognoli S, Chiorrini S, et al. Chemotherapy for advanced gastric cancer: across the years for a standard of care. Expert Opin Pharmacother 2007:8:797-808.

6. Ohtsu A. Current status and future prospects of chemotherapy for metastatic gastric cancer: a review. Gastric Cancer 2005;8: 95-102.

7. Maehara Y. S-1 in gastric cancer: a comprehensive review. Gastric Cancer 2003;6 (Suppl 1):2-8.

8. Lee JL, Kang HJ, Kang YK, Ryu MH, Chang HM, Kim TW, et al. Phase I/II study of 3-week combination of S-1 and cisplatin chemotherapy for metastatic or recurrent gastric cancer. Cancer Chemother Pharmacol 2008;61:837-45.

9. Koizumi W, Kurihara M, Nakano S, Hasegawa K. Phase II study of S-1, a novel oral derivative of 5-fluorouracil, in advanced gastric cancer. Oncology 2000;58:191-7.

10. Nakata B, Mitachi Y, Tsuji A, Yamamitsu S, Hirata K, Shirasaka T, et al. Combination phase I trial of a novel oral fluorouracil derivative S-1 with low-dose cisplatin for unresectable and recurrent gastric cancer (JFMC27-9902). Clin Cancer Res 2004;10:1664-9.

11. Taguchi T, Inuyama Y, Kanamaru R, Hasegawa K, Akazawa S, Niitani H, et al, Phase I study of S-1. Jpn J Cancer Chemother 1997;24:2253-64.

12. Koizumi W, Tanabe S, Saigenji K, Ohtsu A, Boku N, Nagashima F, et al. Phase I/II study of S-1 combined with cisplatin in patients with advanced gastric cancer. Br J Cancer 2003;89:2207-12.

13. Sakata Y, Ohtsu A, Horikoshi N, Sugimachi K, Mitachi Y, Taguchi T. Late phase II study of novel oral fluoropyrimidine anticancer drug S-1 (1 M tegafur- $0.4 \mathrm{M}$ gimestat-1 M otastat potassum) in advanced gastric cancer patients. Eur J Cancer 1998;34:715-20.

14. Baba H, Yamamoto M, Endo K, Ikeda Y, Toh Y, Kohnoe S, et al. Clinical efficacy of S-1 combined with cisplatin for advanced gastric cancer. Gastric Cancer 2003;6 (Suppl 1):45-9.

15. Tsujitani S, Fukuda K, Kaibara N. Combination chemotherapy of S-1 and low-dose cisplatin for advanced gastric cancer. Gastric Cancer 2003;6 (Suppl 1):50-7.

16. Sato Y, Kondo H, Honda K, Takahari D, Sumiyoshi T, Tsuji Y, et al. A phase I/II study of S-1 plus cisplatin in patients with advanced gastric cancer: 2 -week S-1 administration regimen. Int J Clin Oncol 2005;10:40-4.

17. Hyodo I, Nishina T, Moriwaki T, Endo S, Terao T, Hirao K, et al. A phase I study of S-1 combined with weekly cisplatin for metastatic gastric cancer in an outpatient setting. Eur J Cancer 2003;39:2328-33.

18. Kimura Y, Kikkawa N, Iijima S, Kato T, Naoi Y, Hayashi T, et al. A new regimen for S-1 therapy aiming at adverse reaction mitigation and prolonged medication by introducing a 1-week drug-free interval after each 2-week dosing session: efficacy and feasibility in clinical practice. Gastric Cancer 2003;6 (Suppl 1): 34-9.

19. Nagashima F, Ohtsu A, Yoshida S, Ito K. Japanese nationwide post-marketing survey of S-1 in patients with advanced gastric cancer. Gastric Cancer 2005;8:6-11.

20. Chollet P, Schöffski P, Weigang-Köhler K, Schellens JH, Cure H, Pavlidis N, et al. Phase II trial with S-1 in chemotherapy-naïve patients with gastric cancer: a trial performed by the EORTC early clinical studies group (ECSG). Eur J Cancer 2003;39: 1264-70.

21. Ajani JA, Faust J, Ikeda K, Yao JC, Anbe H, Carr KL, et al. Phase I pharmacokinetic study of S-1 plus cisplatin in patients with advanced gastric carcinoma. J Clin Oncol 2005;23:6957-65.

22. Cohen SJ, Leichman CG, Yeslow G, Beard M, Proefrock A, Roedig B, et al. Phase I and pharmacokinetic study of once daily 
oral administration of S-1 in patients with advanced cancer. Clin Cancer Res 2002;8:2116-22.

23. Zhu AX, Clark JW, Ryan DP, Meyechardt JA, Enzinger PC, Earle CC, et al. Phase I and pharmacokinetic study of S-1 administered for 14 days in a 21-day cycle in patients with advanced upper gastrointestinal cancer. Cancer Chemother Pharmacol 2007;59:285-93.

24. Ajani JA, Lee FC, Singh DA, Haller DG, Lenz HJ, Benson AB III, et al. Multicenter phase II trial of S-1 plus cisplatin in patients with untreated advanced gastric or gastroesophageal junction adenocarcinoma. J Clin Oncol 2006;24:663-7.

25. Kelland L. The resurgence of platinum-based cancer chemotherapy. Cancer 2007;7:573-84.

26. Lourvet C, André JM, Tigaud E, Gamelin JY, Douillard, R, Brunet E, et al. Phase II study of oxaliplatin, fluorouracil, and folinic acid in locally advanced or metastatic gastric cancer patients. J Clin Oncol 2002;13:1469-78.

27. De Vita F, Orditura M, Matano E, Bianco R, Carlomagno C, Infusino S, et al. A phase II study of biweekly oxaliplatin plus infusional 5-fluorouracil and folinic acid (FOLFOX-4) as first-line treatment of advanced gastric cancer patients. $\mathrm{Br} \mathrm{J}$ Cancer 2005;92:1644-9.

28. Cavanna L, Artioli F, Codignola C, Lazzaro A, Rizzi A, Gamboni A, et al. Oxaliplatin in combination with 5-fluorouracil (5-FU) and leucovorin (LV) in patients with metastatic gastric cancer (MGC). Am J Clin Oncol 2006;29:371-5.

29. Oh SY, Kwon HC, Seo BG, Kin SH, Kim JS, Kim HJ, et al. A phase II study of oxaliplatin with low dose leucovorin and bolus and continuous infusion 5-fluorouracil (modified FOLFOX-4) as first line therapy for patients with advanced gastric cancer. Acta Oncol 2007;46:336-41.

30. Lee J, Kang WK, Kwon JM, Oh SY, Lee HR, Kim HJ, et al. Phase II trial of irinotecan plus oxaliplatin and 5-fluorouracil/leucovorin in patients with untreated metastatic gastric adenocarcinoma. Ann Oncol 2007;18:88-92.

31. Al-Batran S, Hartmann J, Probst S, Hofheinz R, Stoehlmacher J, Schmalenberg $\mathrm{H}$, et al. A randomized phase III trial in patients with advanced adenocarcinoma of the stomach receiving firstline chemotherapy with fluorouracil, leucovorin and oxaliplatin (FLO) versus fluorouracil, leucovorin and cisplatin (FLP). Proc Am Soc Clin Oncol 2006;2:4016.

32. Park I, Lee J, Ryu M, Chang H, Kim T, Sym S, et al. Phase I/II and pharmacokinetic study of combination chemotherapy with S-1 and oxaliplatin in patients with previously untreated metastatic or recurrent gastric cancer. Proc Am Soc Clin Oncol 2008;26:4557.

33. Boku N, Yamamoto S, Shirao K, Doi T, Sawaki W, Koizumi H, et al. Randomized phase III study of 5-fluorouracil (5-FU) alone versus combination of irinotecan and cisplatin (CP) versus S-1 alone in advanced gastric cancer (JCOG9912). Proc Am Soc Clin Oncol 2007;25:4513.

34. Narahara H, Koizumi W, Hara T, Takagane T, Akiya M, Takagi $\mathrm{K}$, et al. Randomized phase III study of S-1 alone versus S-1 + cisplatin in the treatment for advanced gastric cancer (the SPIRITS trial) SPIRITS: S- 1 plus cisplatin vs S- 1 in RCT in the treatment for stomach cancer. Proc Am Soc Clin Oncol 2007; $25: 4514$ 